\title{
Penguatan Ekonomi dan Ketahanan Pangan Masyarakat Melalui Diversifikasi Produk Gula Aren di Desa Sukahurip Kabupaten Ciamis
}

\author{
Purwati Kuswarini Suprapto, Diki Muhamad Chaidir, Dea Diella, Ryan Ardiansyah \\ Jurusan Pendidikan Biologi, FKIP, Universitas Siliwangi \\ E-mail: dikimc@unsil.ac.id
}

\section{Article History:}

Received: Jan $11^{\text {th }} 2020$

Revised: May 20th 2020

Accepted: Nov 2020

Keywords: palm sugar, product diversification, participatory rural appraisal (PRA).

\begin{abstract}
The palm sugar farmers of Sukahurip Village Ciamis District had difficulty in diversifying their palm sugar into high value and quality products. They felt the need to increase the knowledge and skills of increasing production value and product diversification. Based on the problem, this community service carried out training with the Participatory Rural Appraisal (PRA) approach in which the partners participate in activities carried out in partner locations. The team had succeeded in making a liquid palm sugar formulation that was suitable for use, which previously was the main obstacle experienced by the partners. The results of the focus group discussion (FGD) show that the partners will continue to evaluate the diversification of palm sugar products to maintain the best quality in the hope that they will export the products and become superior to partner villages. The partners will also market the products to a wider community and follow-up from the Ciamis district government and the province.
\end{abstract}

\section{Pendahuluan}

Indonesia merupakan negara dengan tingkat sumber daya alam yang tinggi. ${ }^{1}$ Setiap daerah di Indonesia biasanya memiliki sumber daya alam yang khas sehingga pemanfaatan yang digunakan oleh masyarakat di Indonesia cukup variatif. Salah satunya di Desa Sukahurip, kecamatan Cihaurbeuti, Kabupaten Ciamis. Desa sukahurip khususnya dusun Palasari sebagian besar masyarakat berprofesi sebagai petani,

${ }^{1}$ Herdis HerdM. T. Sirait, B. White, and U. Pradhan, "Chapter 9 - Land Rights and Land Reform Issues for Effective Natural Resources Management in Indonesia," in Redefining Diversity \& Dynamics of Natural Resources Management in Asia, Volume 1, ed. Ganesh P. Shivakoti, Ujjwal Pradhan, and Helmi (Elsevier, 2017), 141-155, accessed December 2020, http://www.sciencedirect.com/science/article/pii/B9780128054543000098.iansyah et al., "Conflict Management of Renewable Natural Resources in the Border of Indonesia-Malaysia: Sustainable Environmental Approach," Procedia Environmental Sciences 20, The 4th International Conference on Sustainable Future for Human Security SUSTAIN 2013 (January 1, 2014): 444-450. 
terutama untuk pertanian organik, karena Dusun Palasari ini mempunyai kelompok khusus dengan nama Ecovillage ANNADOPAH yang banyak bergerak di bidang pengelolaan Sumber Daya Alam (SDA) khususnya pertanian dan pengelolaan sampah dalam rangka peningkatan ekonomi masayarakat. Wilayah tersebut berbatasan langsung dengan hutan yang terdapat di Gunung Sawal, Kabupaten Ciamis, yang merupakan wilayah yang masih menyimpan keragaman flora dan fauna yang perlu mendapatkan perhatian khusus. Keragaman sumber daya alam terutama yang dapat dijadikan pangan ini merupakan salah satu bentuk tolak ukur yang harus dipenuhi dalam ketahanan pangan nasional ${ }^{2}$. Salah satu sumber daya alam yang dimanfaatkan di Desa Sukahurip adalah gula aren yang berasal dari pohon Arena atau enau (Arenga pinnata Merr).

Pohon aren termasuk ke dalam salah satu keluarga pohon palma (Arecaceae) yang memiliki potensi yang cukup banyak, semua bagian tubuh dalam pohon aren dapat dimanfaatkan, baik buah, akan dan daunnya selait itu salah satunya untuk nilai ekonomi, nilai sosial, nilai ekologi yang penting bagi masyarakat sekitar ${ }^{3}$. Pohon aren dapat tumbuh subur di wilayah tropis seperti Indonesia, meskipun dapat tumbuh pada segala macam kondisi tanah, baik tanah berlempung, berkapur maupun berpasir namun pohon aren tidak dapat tumbuh pada tanah yang memiliki kadar asam yang tinggi. Di Indonesia, tanaman aren dapat berkembangan dengan baik dan berproduksi secara optimal pada tanah yang memiliki ketinggian di atas 1.200 meter di atas permukaan laut dengan suhu udara rata-rata $25^{\circ} \mathrm{C}$, di luar daerah tersebut, pohon aren masih tetap dapat tumbuh namun kurang optimal dalam berproduksi ${ }^{4}$. Pohon aren juga merupakan komoditas perkebunan yang memiliki kesesuaian agroklimat dengan kondisi tropis Indonesia dan bernilai ekonomi tinggi ${ }^{56}$. Tanah yang gembur atau kondisinya sesuai untuk meneruskan kelebihan air, tepian sungai dan tanah vulkanis merupakan lahan yang baik untuk pertumbuhan aren 7 .

\footnotetext{
2 Achmad Suryana, "Menuju Ketahanan Pangan Indonesia Berkelanjutan 2025: Tantangan Dan Penanganannya," Forum penelitian Agro Ekonomi 32, no. 2 (2014): 123.

${ }^{3}$ Nurjaya, "The Effect of Service Quality on Consumer Satisfaction of Palm Sugar in West Java," International Journal of Research -GRANTHAALAYAH 7, no. 12 (2020): 231-238; Vijesh V. Krishna and Christoph Kubitza, "Impact of Oil Palm Expansion on the Provision of Private and Community Goods in Rural Indonesia," Ecological Economics 179 (January 1, 2021): 106829; Jonida Bou Dib et al., "Land-Use Change and Livelihoods of Non-Farm Households: The Role of Income from Employment in Oil Palm and Rubber in Rural Indonesia," Land Use Policy 76 (July 1, 2018): 828-838; Tania Murray Li, "After the Land Grab: Infrastructural Violence and the 'Mafia System' in Indonesia's Oil Palm Plantation Zones," Geoforum 96 (November 1, 2018): 328-337; Juepeng Zheng et al., "Cross-Regional Oil Palm Tree Counting and Detection Via a Multi-Level Attention Domain Adaptation Network," ISPRS Journal of Photogrammetry and Remote Sensing 167 (September 1, 2020): 154-177.

${ }^{4}$ Natsir Mohammad \& Dahlam Lama Bawa, "IBM Kelompok Usaha Gula Aren Di Sekitar Kawasan Hutan Kabupaten Gowa," Majalah Aplikasi Ipteks NGAYAH Volume 7, Nomor2,Desember 2016 7, no. 2 (2016).

5 Candra Nuraini and Unang Atmaja, "Palm Sugar Agribusiness Development Strategy in Tasikmalaya Regency," Agriekonomika 8, no. 1 (2019): 62.

6 Benny Rachman, "Karakteristik Petani dan Pemasaran Gula Aren Di Banten," Forum penelitian Agro Ekonomi 27, no. 1 (2017): 53.

${ }^{7}$ Mody Lempang, "Pohon Aren Dan Manfaat Produksinya," Info Teknis EBONI 9, no. 1 (2012): 37-
} 
Pohon aren banyak tumbuh di sekitar kawasan hutan milik masyarakat yang ada di desa Sukahurip, akan tetapi saat ini pohon aren tersebut belum banyak dimanfaatkan untuk produk lainnya. Pohon aren merupakan salah satu tumbuhan yang biasa dimanfaatkan sebagai hasil hutan bukan kayu (HHBK) yang dapat meningkatkan atau memberikan pendapatan bagi masyarakat ${ }^{8}$, sehingga pemanftaan pohon aren juga bisa dilakukan dengan prinsip keberlanjutan. Menurut masyarakat sekitar sampai saat ini pohon aren hanya dimanfaatkan sebatas untuk buahnya serta air niranya yang dijadikan gula aren, sehingga nilai pemanfaatannya masih tergolong rendah dan akan mengalami kesulitan dalam nilai ekonomi pohon aren tersebut. Padahal kebutuhan gula nasional terus bertambah seiring dengan bertambahnya jumlah penduduk, meningkatnya pendapatan, dan industri yang menggunakan gula aren sebagai bahan baku utamanya ${ }^{9}$.

Pohon aren yang ditumbuh disekitar hutan desa merupakan hasil penyebaran biji secara alami yang dilakukan oleh hewan yang berada di sekitar lokasi hutan. Menurut informasi masyarakat desa sekitar pohon aren yang tumbuh biasanya berasal dari bekas buah yang dimakan oleh hewan musang luwak dan babi hutan, dikarenakan apabila biji tersebut ditanam dengan sengaja oleh masyarakat sekitar biasanya tidak tumbuh dan berkembang dengan baik. Akan tetapi dari bekas biji yang telah dimakan buahnya oleh kedua hewan tersebut, ternyata hanya yang berasal dari musang luwak yang biasanya memiliki hasil yang lebih baik, petani di sana sudah mengetahui perbedaan dari keduanya, sehingga biasanya pohon aren yang berasal dari babi hutan biasanya hanya dimanfaatkan batang dan daunnya saja, karena tidak dapat menghasilkan gula aren yang baik. Selain itu juga pohon aren sangat dipengaruhi oleh musim, biasanya aren pada musim kemarau mempunyai kualitas yang lebih baik ${ }^{10}$.

Di desa Sukahurip ini, produk utama yang digunakan dari pohon aren ini adalah nira yang diambil langsung dengan cara tertentu dari pohon aren kemudian diolah dan diproduksi menjadi gula aren padat. Gula aren padat yang diproduksi biasanya masih dalam bentuk kemasan yang relatif besar dan kurang praktis agar lebih cepat terjual saja, dikarenakan pekerjaan ini masih dianggap sebagai pekerjaan sampingan. Dalam bentuk pengemasan yang demikian mengakibatkan nilai tambah untuk produk gula aren tersebut masih relatif kecil, masyarakat sekitar juga mengalami kesulilatan dalam hal pemasaran ${ }^{11}$, karena produknya dengan produksi demikian hanya mencapai lokasi

8 Makkarennu, Fikri Muh. Rum, and Ridwan, "Analisis Pendapatan Usaha Gula Aren Pada Masyarakat" 14, no. 2 (2018): 61-65.

${ }_{9}^{9}$ Baharuddin, Musrizal Muin, and Dan Herniaty Bandaso, "Pemanfaatan Nira Aren (Arenga Pinnata Merr) Sebagai Bahan Pembuatan Gula Putih Kristal The Useful Nira Aren (Arenga Pinnata Merr) as Raw Material for Making White Refined Sugar," Jurnal Perennial 3, no. 2 (2007): 40-43.

10 Dyah Rasti, Agus Setiadi, and Kustopo Budiraharjo, "Factors That Affect the Income of Artisan Palm Sugar Maker in Candimulyo," SOCA: Jurnal Sosial Ekonomi Pertanian 14, no. 3 (2020): 444-455.

11 Moch Khafidz Fuad Raya, "Marketing Jasa Di Institusi Pendidikan (Analisis Pemasaran Dalam Pendidikan)," FALASIFA : Jurnal Studi Keislaman 7, no. 1 (April 15, 2016): 21-52; Kannan Govindan et al., "Marketing Issues for Remanufactured Products," Journal of Cleaner Production 227 (August 1, 2019): 890899. 
sekitar desa saja. Selain itu sedikit penggunaan teknologi dalam pembuatannya juga membuat produktivitas yang dilakukan cenderung rendah ${ }^{12}$. Upaya dalam diversifikasi produk gula aren belum dilakukan di desa ini, padahal potensi produk dari bahan dasar yang sama sudah banyak dilakukan di wilayah lain seperti pembuatan sirup gula aren, gula semut dan lainnya yang mempunyai permintaan cukup tinggi di pasaran. Sehingga sangat perlu dilakukan pembaharuan untuk menambah nilai produksi yang nilai manfaatnya dapat dirasakan langsung oleh masyarakat sekitar, agar hasil gula aren menjadi potensi dalam menambah penghasilan bagi para petani ${ }^{13}$.

Penambahan nilai produk gula aren lokal yang ada di desa Sukahurip sangat penting perananannya bagi masyarakat yang tinggal di kawasan sekitar hutan desa, terutama dalam pemanfaatan hasil hutan bukan kayu yang banyak manfaatnya untuk sumber pangan alternatif lainnya untuk kebutuhan ketahanan pangan masyarakat desa. Selain itu, upaya peningkatan kesejahteraan dengan penambahan nilai produk, dapat secara langsung mengurungai bagaimana pengaruh terhadap kerusakan hutan. Apalagi hutan yang ada di sekitar desa berbatasan langsung dengan kawasan konservasi Suaka Margasatwa Gunung Sawal, Kabupaten Ciamis yang rawan terjadi konflik sumberdaya dengan masayarakat. Tujuan dari kegiatan ini adalah memberikan pengetahuan dan pelatihan kepada masyarakat tentang diversifikasi produk gula aren sebagai nilai ekonomi dan ketahanan pangan di masa pandemi covid-19 ini. Seharusnya dapat menjadikan produk tersebut sebagai bentuk ketahanan pangan masyarakat dan memenuhi penguatan ekonomi masyasakat desa Sukahurip secara berkelanjutan.

\section{Metode}

Untuk mencapai tujuan, target dan luaran kegiatan pengabdian pada masyarakat tentang pengembangan produk gula aren lokal untuk ketahanan pangan dan penguatan ekonomi masyarakat desa sukahurip kabupaten Ciamis pada masa pandemi covid-19, media yang dilakukan adalah dengan cara partisifpatif, demontrasi, pembinaan dan brainstorming. Pendekatan yang digunakan adalah dengan menggunakan PRA (Participatory Rural Apprasial) dimana dalam progam kegiatannya melibatkan secara parsipatif mitra kegiatan dan kegiatan yang dilaksanakan di lokasi mitra. Dalam kegiatannya pengkajian potensi sumber daya alam dan pemasalahan yang ditemukan dilakukan oleh pihak mitra, hingga masyarakat juga ikut mengambil peran dalam membuat penilaian, menganalisa dan mengeveluasi tentang program yang telah dilaksanakan, sehingga kerja sama yang terjalin dengan mitra tidak hanya dilakukan

12 Suliyanto, W. Novandari, and Suwaryo, "How to Improve the Competitiveness of Palm Sugar? The Role of Technical Innovation," IOP Conference Series: Earth and Environmental Science 255, no. 1 (2019).

13 Makkarennu, A. A. Rizaldy, and A. S. Mahbub, "Marketing Strategic and Competitive Positioning of Palm Sugar Business Development," IOP Conference Series: Earth and Environmental Science 270, no. 1 (2019). 
pada saat kegiatan saja, tetapi bisa berlanjut menjadi suatu desa binaan yang dapat terus dilakukan program lainnya hingga desa mencapai suatu desa yang mandiri dan maju secara ekonomi dan pengetahuan dalam pengelolaan potensi sumber daya yang ada.

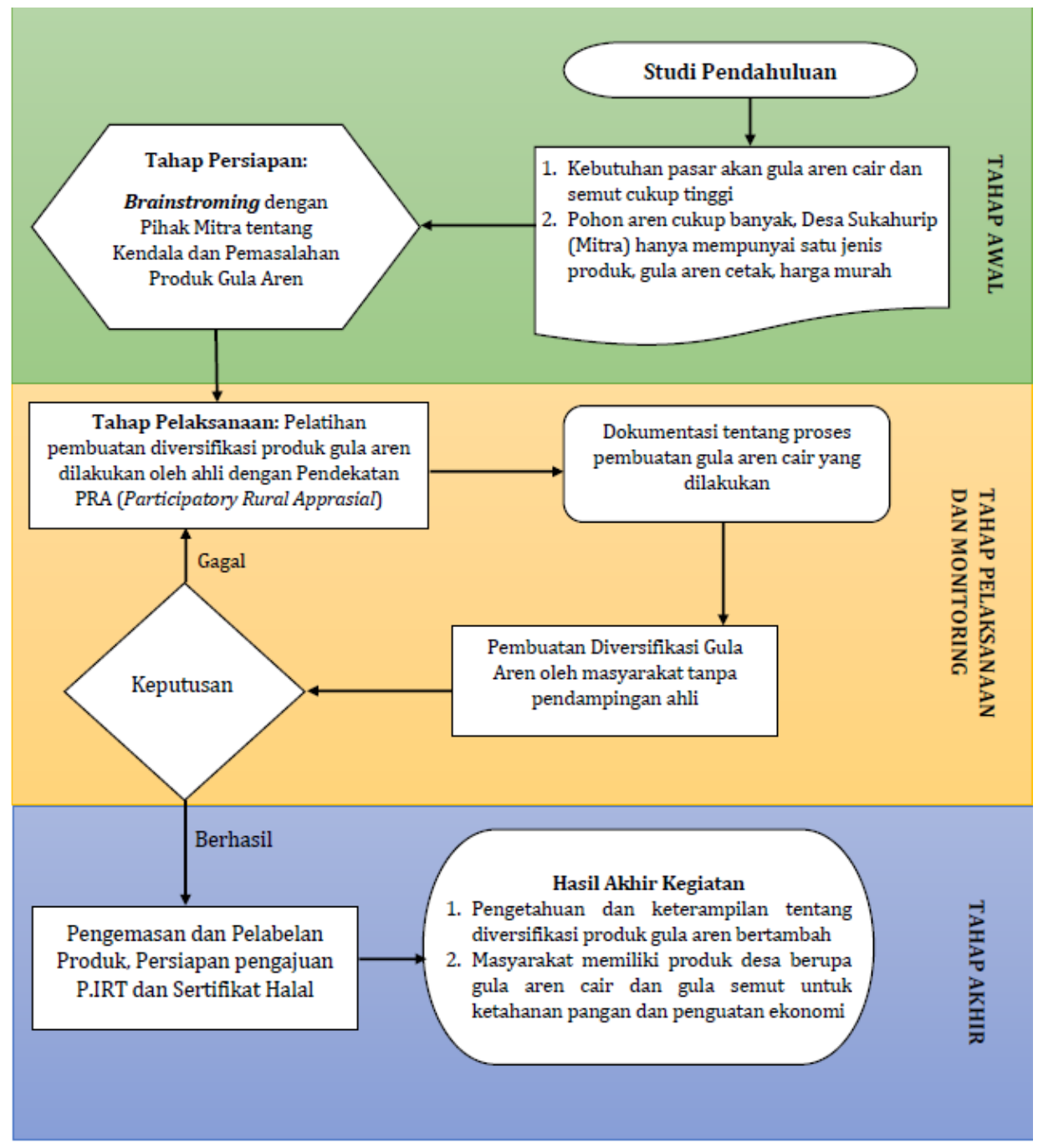

Gambar 1. Diagram Alir Kegiatan Pengabdian

Dalam kegiatan ini akan terlebih dahulu dilakukan brainstorming bersama pihak mitra, untuk melihat lebih dalam bagaimana permasalahan serta analisis kendala dan pemasalahan tentang produk gula aren yang sebelumnya dibuat oleh masyarakat desa, kemudian mitra akan diberikan tentang bagaimana strategi dalam ketahanan pangan dan penguatan ekonomi berdasarkan sumber daya alam yang ada terutama yang berasal dari pohon aren. Setelah itu akan dilakukan pelatihan diversifikasi produk gula aren yang dilakukan bersama mitra hingga menemukan formulasi yang sesuai, setelah itu pembuatan merek dagang yang mencerminkan karakteristik khas desa Sukahurip yang nantinya menjadi salah satu komoditi utama yang dapat dihasilkan oleh desa secara berkelanjutan, pemasaran produk dengan melibatkan berbagai pemangku kepentingan serta kerja sama dengan berbagai pihak terkait. Hingga dibuatnya buku khusus bagaimana pengolahan dan diversifikasi produk gula aren lokal yang dibuat oleh 
masyarakat desa Sukahurip, yang juga akan menjadi daya tarik tambahan tentang potensi desa. Selain itu dengan adanya kegiatan ini diharapkan desa Sukahurip akan lebih dikenal oleh masyarakat luas dan menjadi salah satu desa percontohan yang maju dalam berbagai aspek terutama ekonomi dan ekosistem yang berkelanjutan yang memberikan manfaat bagi masyarakat maupun pemanfatan sumber daya alam yang ada di lingkungan sekitar secara lestari dan berdasarkan prinsip tujuan pembangunan berkelanjutan atau lebih dikenal dengan Sustainable Development Goals (SDGs).

\section{Hasil dan Diskusi}

Pengabdian bagi Masyarakat tentang pendampingan produk gula aren lokal untuk ketahanan pangan dan penguatan ekonomi masyarakat desa sukahurip kabupaten Ciamis di masa pandemi Covid-19 telah dilaksanan sejak bulan September hingga terus dilakukan monitoring dan evalusi pada bulan November 2020. Kegiatan diawali dengan melakukan fokus grup diskusi dan brainstorming persiapan akan diadakannya kegiatan pengabdian PbM-KP pada pihak mitra yaitu kelompok ecovillage ANNDOPAH dan Desa Sukahurip. Pada tahap ini dilakukan tahap diskusi bersama terkait tempat kegiatan, jumlah masyarakat yang hadir serta perlatan yang dibutuhkan oleh mitra dalam proses diversifikasi produk gula aren. Kegiatan ini dilakukan di rumah salah satu masyarakat dengan melihat langsung bagaimana proses pembuatan gula aren yang biasa dilakukan oleh masyarakat.

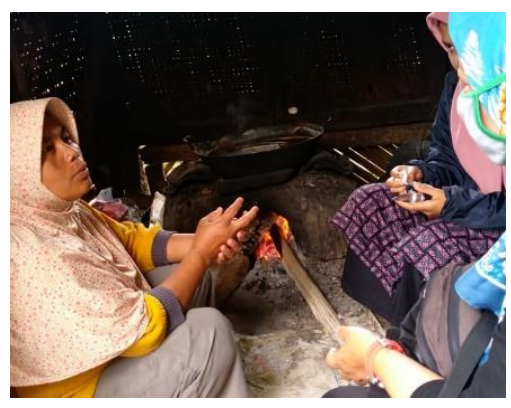

Gambar 2. Diskusi yang dilakukan bersama salah satu masyarakat

Kegiatan yang dilakukan selanjutnya adalah mencatat berbagai informasi data kembali tentang gula aren dan diversifikasi produknya yang telah dibuat oleh masyarakat mitra. Dalam kegiatan ini juga mencari informasi berapa harga jual gula aren cetak, pemasaran, dan pengemasan produk yang biasa dibuat oleh mitra. Pada umunya berdasarkan informasi yang diperoleh, gula aren yang dibuat oleh masyarakat masih berdasarkan pengetahuan turun temurun, padahal jika didokumentasikan dengan baik, hal ini bisa menjadi pengetahuan tentang sains yang bermanfaat ${ }^{14}$. Setelah itu mencoba

14 Woro Sumarni et al., "The Reconstruction of Society Indigenous Science into Scientific Knowledge in the Production Process of Palm Sugar," Journal of Turkish Science Education 13, no. 4 (2016): 
merumuskan berbagai strategi dalam upaya mengembangkan produk aren yang ada. Sama seperti pada petani gula aren lainnya di wilayah lain, biasanya jika tidak terdapat pesanan hanya dijual murah kepada para masyarakat sekitar atau pedagang lokal ${ }^{15}$.

Materi utama yang diberikan mengenai bagiamana membuat berbagai jenis olahan gula aren lainnya yang memiliki nilai ekonomi lebih dibandingkan dengan gula padat pada umumnya yaitu produk gula aren cair dan gula semut. Pelatihan yang dilakukan dibantu oleh 6 orang mahasiswa yang didampingi oleh tim pengabdian dan mengundang narasumber yang sudah ahli dalam membuat gula aren cair hingga mencapai kualitas ekspor. Dalam penyampaian materi dilakukan dengan pelatihan langsung pembuatan gula aren setelah itu analisis kualitas dari fisik dan kimia gula aren, yaitu warna, suhu, terutama $\mathrm{pH}$ dan kadar gula (brix) dari nira aren yang baru diambil. Perhitungan tersebut dilakukan dengan menggunakan alat khusus untuk mengukur $\mathrm{pH}$ yaitu dengan $\mathrm{pH}$ meter digital dan kadar gula dengan Refractometer Brix.

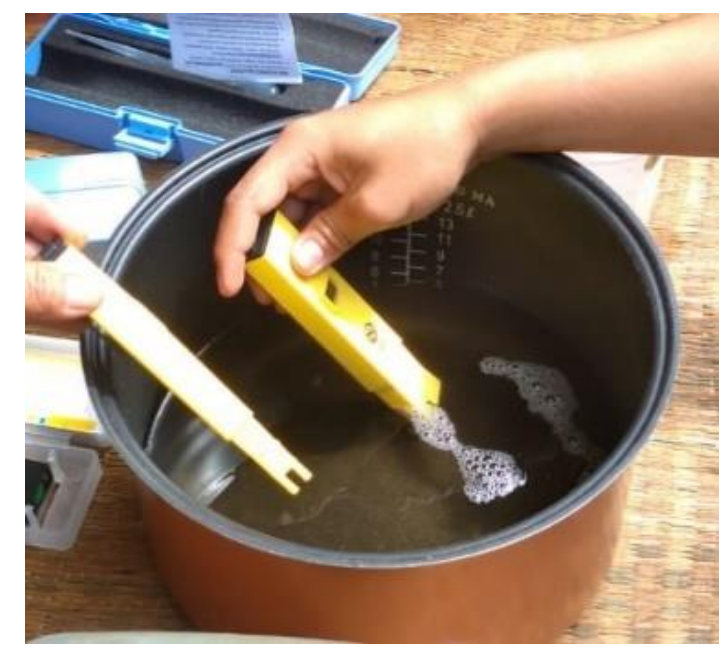

Gambar 3. Proses analisis kualitas Nira menggunakan $\mathrm{pH}$ meter

Dalam proses pembuatan, nira segar yang baik memiliki kualitas pH antara 5,5 7, memiliki rasa yang manis dan warna bening agak hijau kecoklatan 16. Pada saat kegiatan $\mathrm{pH}$ yang diukur dari Nira yang ada di desa tersebut memiliki pH 5,7, dan pengukuran kadar gula dengan refractometer brix 13\%, hal ini menandakan kualitas nira yang ada pada desa tergolong baik, hal ini dilihat dari kadar gula ideal antara $10-20 \%$ untuk dapat menghasilkan gula aren ${ }^{17}$. Hal ini juga tentu saja sangat dipengaruhi oleh waktu pengambilan nira dari pohon arennya yang tidak lebih dari 2 jam. Pengukuran $\mathrm{pH}$

281-292.

15 Rosidah R Radam and Arfa Agustina Rezekiah, "Pengolahan Gula Aren (Arrenga Pinnata Merr) Di Desa Banua Hanyar Kabupaten Hulu Sungai Tengah," Jurnal Hujan Tropis 3, no. 3 (2015): 267-276.

16 Sri Winarni et al., "Nira Acidity and Antioxidant Activity of Palm Sugar in Sumowono Village," Journal of Physics: Conference Series 1025, no. 1 (2018).

17 Teguh Kurniawan et al., "Palm Sap Sources, Characteristics, and Utilization in Indonesia," Journal of Food and Nutrition Research 6, no. 9 (2018): 590-596. 
diawal proses pembuatan ini sangat penting, karena dalam beberapa hal ini juga akan berpengaruh kepada hasil akhir kadar gula aren ${ }^{18}$. Setelah itu dilakukan pemasakan nira aren tersebut pada tungku dan pengapian yang masih mengandalakan kayu bakar. Pemasakan air nira dilakukan dengan memperhatikan suhu dan kadar gula yang ada hingga mencapai batas suhu maksimal yang dilakukan adalah $110^{\circ}$ celcius dan brix mencapai sekitar 70\%, kemudian api dimatikan. Proses pemasakan dengan memperhatikan suhu ini sangat penting karena akan mempengaruhi perubahan dari segi fisik maupun kimia dari nira aren yang dimasak tersebut ${ }^{19}$. setelah itu gula aren yang dimasak ditiriskan dan disaring dalam saringan khusus kemudian dimasukan ke dalam botol sesuai ukuran. Pada saat pengukuran akhir didapatkan kadar brix menurun menjadi sekitar 60\%, untuk pH ditahap akhir tidak diukur, karena sampai ini belum ada Standar Nasional Indonesia untuk prasayarat $\mathrm{pH}$ yang ditentukan ${ }^{20}$.

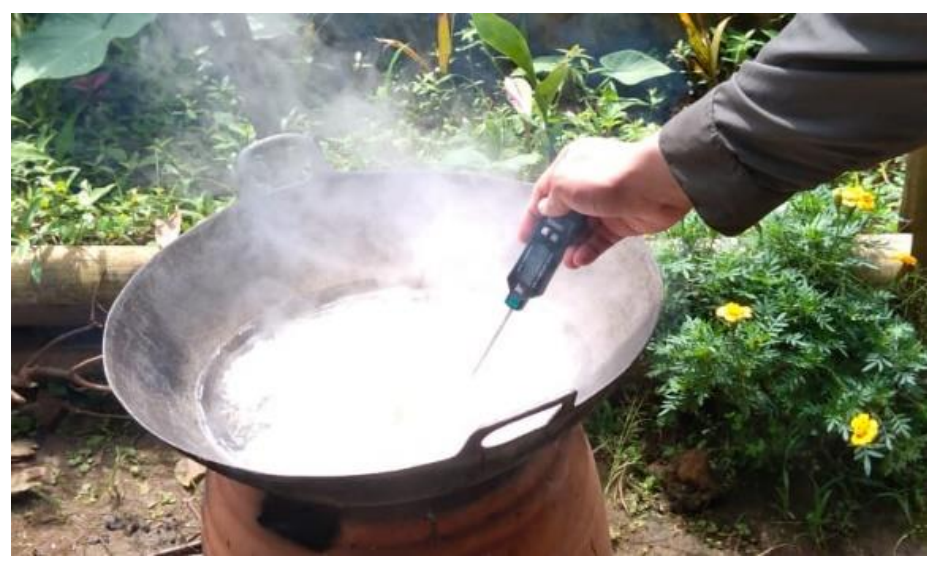

Gambar 4. Proses pengukuran suhu gula aren yang sedang dimasak

Berdasarkan hasil diskusi yang dilakukan, jumlah nira aren yang menghasilkan gula aren cair lebih banyak dibandingkan dengan membuat gula aren cetak, dikarenakan dengan gula cetak penyusutan semakin tinggi. Selama proses pembuatan gula aren cair ini, dicatat berbagai prosedur yang dilakukan dan dibuatlah sebuah SOP (Standart Operational Prosedur) pembuatan gula aren cair yang dapat digunakan oleh mitra sebagai acuan dalam membuat gula aren cair lagi nantinya. Pembuatan SOP ini sangat penting, karena pembuatan gula aren secara tradisional biasanya masih tidak konsisten dalam kualitas maupun pengukuran variabel lainnya dalam proses pembuatan ${ }^{21}$. Selain itu diversifikasi produk yang berhasil dibuat adalah gula semut, gula semut ini juga menjadi

${ }^{18}$ Inneke Victor and Valérie Orsat, "Characterization of Arenga Pinnata (Palm) Sugar," Sugar Tech 20, no. 1 (2018): 105-109.

${ }^{19}$ P Naknean, M Meenune, and G Roudaut, "Changes in Physical and Chemical Properties during the Production of Palm Sugar Syrup by Open Pan and Vacuum Evaporator.," Asian Journal of Food and AgroIndustry 2, no. 4 (2009): 448-456.

${ }^{20}$ Kurniawan A. Saputra, "Analisis Kandungan Asam Organik Pada Beberapa Sampel Gula Aren," Jurnal MIPA 4, no. 1 (2015): 69.

${ }^{21} \mathrm{C}$ W Ho et al., "Effect Of Thermal Processing Of Palm Sap on the Physco-Chemical Composition of Thailand Palm Sugar," Pakistan Journal of Biological Sciences, 2008. 
potensi nilai tambah produk sebagai pengolahan lanjutan ${ }^{22}$, karena bisnis gula semut ini memiliki relatif harga lebih tinggi dibandingkan hanya dengan bentuk gula cetak biasa ${ }^{23}$.

Kegiatan selanjutnya adalah pengemasan produk gula aren cair yang sudah dibuat, pengemasan dilakukan dengan menggunakan botol plastik ukuran khusus yaitu ukuran $100 \mathrm{ml}$ dan $250 \mathrm{ml}$. Botol plastik disini digunakan karena dianggap lebih fleksibel, ringan, mudah dibawa dan terjangkau ${ }^{24}$. Setelah itu dilakukan dengan pelabelan produk dengan merk "Beleketebe" yang berasal dari nama tumbuhan Slonea sigun atau sebutan lain Ki somang, juga merupakan ikon salah satu curug/ air terjun yang ada di dusun Palasari desa Sukahurip, yang berada di kaki Gunung Sawal. Pelabelan yang dilakukan berdasarkan hasil diskusi yang dilakukan serta kesesuaian produk yang dibuat, serta komposisi dan produksi. Isi pelabelan mencakup merek gula, jensi gula aren, komposisi, produksi dan saran penyimpanan. Isi pelabelan ini penting untuk mengetahui tentang produk yang dibuat, serta saran penyimpanan yang akan berpengaruh terhadap umur simpan dari gula aren ${ }^{25}$. Hanya saja produk yang dibuat belum mencakup untuk Surat Izin Produk Industri Rumah Tinggi (PIRT) dan sertifikat halal dari Majelis Ulama Indonesia (MUI), yang ini akan dilakukan prosesnya dalam waktu dekat.

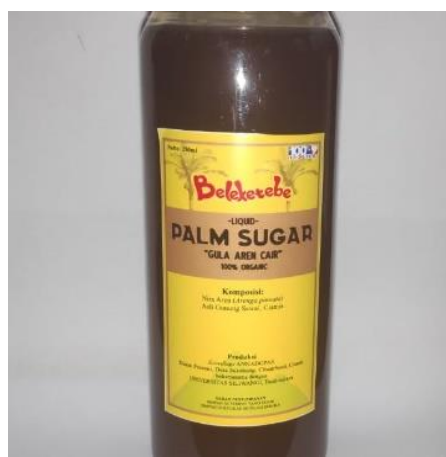

(A)

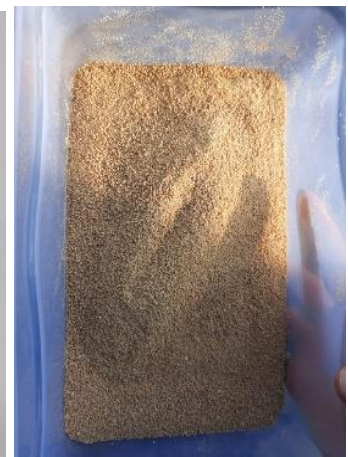

(B)

Gambar 5. Hasil diversifikasi produk gula aren yang dibuat bersama mitra (A) Gula Aren Cair (B) Gula Semut

Seluruh kegiatan yang sudah dilakukan kemudian dilakukan wawancara langsung kepada masyarakat dan pembuatan angket kepada mitra mengenai kepuasan program kegiatan yang telah dilakukan. Berdasarkan wawancara dan angket yang telah diberikan, masyarakat merasakan pengetahuan yang didapatkan karena sesuai dengan kebutuhan dan harapan terhadap kegiatan. Masyarakat saat ini sudah terbiasa dalam pembuatan

${ }^{22}$ Himmatul Miftah, Arti Yusdiarti, and Harry Maulana, "Analisis Nilai Tambah Olahan Gula Aren Di Kelompok Usaha Bersama (Kub) Gula Semut Aren (Gsa),” Jurnal Agribisains 4, no. 2 (2019): 8-14.

${ }^{23}$ G H Joseph Dan and Payung Layuk, "Pengolahan Gula Semut Dari Aren," Buletin Palma 13, no. 1 (2016): 60-65.

24 M. L. Sanyang et al., "Sugar Palm Starch-Based Composites for Packaging Applications," Bionanocomposites for Packaging Applications (2017): 125-147.

25 Erni; Nazaruddin; Rusdin Romansyah, "Pendugaan Umur Simpan Gula Semut Dalam Kemasan Dengan Pendekatan Arrhenius," Jurnal Ilmiah Rekayasa Pertanian dan Biosistem, Vol. 7, No. 2, September 2019 7, no. 2 (2019): 249-257. 
diversifikasi produk gula aren, termasuk dalam penggunaan peralatan yang dibutuhkan. Kegiatan yang dilakukan secara berkelanjutan, serta mitra berminat mengikuti kegiatan pengabdian lainnya jika dilakukan. Jadi secara keseluruhan, masyarakat merasa puas dengan seluruh rangakaian kegiatan pengabdian yang telah dilakukan. Pihak mitra juga akan terus melakukan evaluasi terhadap produk yang telah dibuat, serta mengenalkan produk yang telah dibuat untuk diperkenalkan kepada pemerintah terkait juga masyarakat lebih luas. Sinergitas masyarakat, petani, pelaku usaha dan pemerintah memiliki peran penting untuk dapat menghadapi peluang dan tantang dari produksi gula aren ini ${ }^{26}$. Besar harapannya desa Sukahurip ini menjadi perintis dan sentra produksi dalam diversifikasi produk gula aren di wilayah Ciamis.

\section{Kesimpulan}

Kegiatan Pengabdian bagi Masyarakat pada skema ketahan pangan (PbM-KP) tentang Pengembangan produk gula aren lokal untuk ketahanan pangan dan penguatan ekonomi masyarakat desa sukahurip kabupaten Ciamis di masa pandemi Covid-19 telah dilaksanan sejak bulan September hingga terus dilakukan monitoring dan evalusi pada bulan November tahun 2020. Kegiatan yang telah dilaksanakan selama ini berjalan dengan lancar tanpa adanya kendala yang berarti serta diharapkan dapat meberikan manfaat bagi mitra dalam upaya ketahanan pangan dan penguatan ekonomi masyarakat mitra.

Berdasarkan hasil fokus grup diskusi yang telah dilakukan dengan pihak mitra, pihak mitra akan terus berupaya melakukan evaluasi terhadap diversifikasi produk gula aren yang telah dibuat hingga mencapai produk yang benar-benar memiliki kualitas terbaik hingga harapnya dapat menjadi produk ekspor dan produk unggulan desa. Secara kesuluruhan kegiatan yang dilakukan, masyarakat merasa puas dengan program yang sudah dilakukan. Pihak mitra juga akan terus melakukan berbagai upaya agar produk yang telah dibuat lebih dikenal masyarakat sekitar terutama produk gula aren cair maupun gula semut yang telah dibuat oleh kelompok Ecovillage ANNADOPAH dan Desa Sukahurip. Upaya lainnya pihak mitra akan mengenalkan produk ini ke pihak pemerintah kabupaten agar mendapat dukungan penuh juga menjadi salah satu produk unggulan di wilayah Kabupaten Ciamis. Besar harapannya desa Sukahurip ini menjadi perintis dan sentra produksi dalam diversifikasi produk gula aren di wilayah Ciamis.

\section{Pengakuan}

Penulis mengucapkan terima kasih kepada LPPM-PMP (Lembaga Penelitian dan Pengabdian Pada Masyarakat - Penjamin Mutu Pendidikan) Universitas Siliwangi, karena kegiatan pengabdian pada masyarakat ini didanai dengan kegiatan Pengabdian bagi bina

${ }^{26}$ Nuraini and Atmaja, "Palm Sugar Agribusiness Development Strategy In Tasikmalaya Regency." 
masyarakat skema ketahan pangan. Penulis juga mengucapkan terima kasih kepada Kepala Desa Sukahurip dan Ketua Kelompok Ecovillage ANNADOPAH (Pak Dadang, S.Pd.I. yang telah menginzinkan dan memberi masukan terhadap kegiatan pelatahin ini. Para mahasiswa dari Universitas Siliwangi yang telah ikut membantu atas terlaksanakanya kegiatan ini, Hanifah, Mulyani, Fajar, Desi, Dedi, Nurul dan lainya.

\section{Daftar Referensi}

Baharuddin, Musrizal Muin, and Dan Herniaty Bandaso. "Pemanfaatan Nira Aren (Arenga Pinnata Merr) Sebagai Bahan Pembuatan Gula Putih Kristal The Useful Nira Aren (Arenga Pinnata Merr) as Raw Material for Making White Refined Sugar." Jurnal Perennial 3, no. 2 (2007): 40-43.

Bou Dib, Jonida, Vijesh V. Krishna, Zulkifli Alamsyah, and Matin Qaim. "Land-Use Change and Livelihoods of Non-Farm Households: The Role of Income from Employment in Oil Palm and Rubber in Rural Indonesia." Land Use Policy 76 (July 1, 2018): 828838.

Dan, G H Joseph, and Payung Layuk. "Pengolahan Gula Semut Dari Aren." Buletin Palma 13, no. 1 (2016): 60-65.

Govindan, Kannan, Beatriz Jiménez-Parra, Sergio Rubio, and María-Azucena VicenteMolina. "Marketing Issues for Remanufactured Products." Journal of Cleaner Production 227 (August 1, 2019): 890-899.

Herdiansyah, Herdis, Budi Susilo Soepandji, Francisia SSE Seda, and Oetami Dewi. "Conflict Management of Renewable Natural Resources in the Border of Indonesia-Malaysia: Sustainable Environmental Approach." Procedia Environmental Sciences 20. The 4th International Conference on Sustainable Future for Human Security SUSTAIN 2013 (January 1, 2014): 444-450.

Ho, C W, Aida W. M. Wan, Maskat M. Y, and H Osman. "Effect Of Thermal Processing Of Palm Sap on the Physco-Chemical Composition of Thailand Palm Sugar." Pakistan Journal of Biological Sciences, 2008.

Krishna, Vijesh V., and Christoph Kubitza. "Impact of Oil Palm Expansion on the Provision of Private and Community Goods in Rural Indonesia." Ecological Economics 179 (January 1, 2021): 106829.

Kurniawan, Teguh, J Jayanudin, Indar Kustiningsih, and Mochamad Adha Firdaus. "Palm Sap Sources, Characteristics, and Utilization in Indonesia." Journal of Food and Nutrition Research 6, no. 9 (2018): 590-596.

Lempang, Mody. "Pohon Aren Dan Manfaat Produksinya." Info Teknis EBONI 9, no. 1 (2012): 37-54.

Li, Tania Murray. “After the Land Grab: Infrastructural Violence and the 'Mafia System' in 
Indonesia's Oil Palm Plantation Zones." Geoforum 96 (November 1, 2018): 328337.

Makkarennu, A. A. Rizaldy, and A. S. Mahbub. "Marketing Strategic and Competitive Positioning of Palm Sugar Business Development." IOP Conference Series: Earth and Environmental Science 270, no. 1 (2019).

Makkarennu, Fikri Muh. Rum, and Ridwan. "Analisis Pendapatan Usaha Gula Aren Pada Masyarakat” 14, no. 2 (2018): 61-65.

Miftah, Himmatul, Arti Yusdiarti, and Harry Maulana. "Analisis Nilai Tambah Olahan Gula Aren Di Kelompok Usaha Bersama (Kub) Gula Semut Aren (Gsa).” Jurnal Agribisains 4, no. 2 (2019): 8-14.

Mohammad, Natsir, and Dahlam Lama Bawa. "IbM KELOMPOK USAHA GULA AREN DI SEKITAR KAWASAN HUTANKABUPATEN GOWA 1." Majalah Aplikasi Ipteks NGAYAH Volume 7, Nomor2,Desember 2016 7, no. 2 (2016).

Naknean, P, M Meenune, and G Roudaut. "Changes in Physical and Chemical Properties during the Production of Palm Sugar Syrup by Open Pan and Vacuum Evaporator." Asian Journal of Food and Agro-Industry 2, no. 4 (2009): 448-456.

Nuraini, Candra, and Unang Atmaja. "Palm Sugar Agribusiness Development Strategy In Tasikmalaya Regency.” Agriekonomika 8, no. 1 (2019): 62.

Nurjaya. "The Effect of Service Quality on Consumer Satisfaction of Palm Sugar in West Java." International Journal of Research -GRANTHAALAYAH 7, no. 12 (2020): 231238.

Rachman, Benny. “Karakteristik Petani Dan Pemasaran Gula Aren Di Banten.” Forum penelitian Agro Ekonomi 27, no. 1 (2017): 53.

Radam, Rosidah R, and Arfa Agustina Rezekiah. "Pengolahan Gula Aren (Arrenga Pinnata Merr) Di Desa Banua Hanyar Kabupaten Hulu Sungai Tengah." Jurnal Hujan Tropis 3, no. 3 (2015): 267-276.

Rasti, Dyah, Agus Setiadi, and Kustopo Budiraharjo. "Factors That Affect the Income of Artisan Palm Sugar Maker in Candimulyo." SOCA: Jurnal Sosial Ekonomi Pertanian 14, no. 3 (2020): 444-455.

Raya, Moch Khafidz Fuad. "Marketing Jasa Di Institusi Pendidikan (Analisis Pemasaran Dalam Pendidikan)." FALASIFA : Jurnal Studi Keislaman 7, no. 1 (April 15, 2016): 21-52.

Romansyah, Erni; Nazaruddin; Rusdin. "Pendugaan Umur Simpan Gula Semut Dalam Kemasan Dengan Pendekatan Arrhenius." Jurnal Ilmiah Rekayasa Pertanian dan Biosistem, Vol. 7, No. 2, September 2019 7, no. 2 (2019): 249-257.

Sanyang, M. L., R. A. Ilyas, S. M. Sapuan, and R. Jumaidin. "Sugar Palm Starch-Based 
Composites for Packaging Applications." Bionanocomposites for Packaging Applications (2017): 125-147.

Saputra, Kurniawan A. "Analisis Kandungan Asam Organik Pada Beberapa Sampel Gula Aren.” Jurnal MIPA 4, no. 1 (2015): 69.

Sirait, M. T., B. White, and U. Pradhan. "Chapter 9 - Land Rights and Land Reform Issues for Effective Natural Resources Management in Indonesia." In Redefining Diversity \& Dynamics of Natural Resources Management in Asia, Volume 1, edited by Ganesh P. Shivakoti, Ujjwal Pradhan, and Helmi, 141-155. Elsevier, 2017. Accessed December 20 , 2020. http://www.sciencedirect.com/science/article/pii/B9780128054543000098.

Suliyanto, W. Novandari, and Suwaryo. "How to Improve the Competitiveness of Palm Sugar? The Role of Technical Innovation." IOP Conference Series: Earth and Environmental Science 255, no. 1 (2019).

Sumarni, Woro, Sudarmin, Wiyanto, and Supartono. "The Reconstruction of Society Indigenous Science into Scientific Knowledge in the Production Process of Palm Sugar." Journal of Turkish Science Education 13, no. 4 (2016): 281-292.

Suryana, Achmad. "Menuju Ketahanan Pangan Indonesia Berkelanjutan 2025: Tantangan Dan Penanganannya." Forum penelitian Agro Ekonomi 32, no. 2 (2014): 123.

Victor, Inneke, and Valérie Orsat. "Characterization of Arenga Pinnata (Palm) Sugar." Sugar Tech 20, no. 1 (2018): 105-109.

Winarni, Sri, Fahmi Arifan, R. T.D. Wisnu Broto, Ariza Fuadi, and Lola Alviche. "Nira Acidity and Antioxidant Activity of Palm Sugar in Sumowono Village." Journal of Physics: Conference Series 1025, no. 1 (2018).

Zheng, Juepeng, Haohuan Fu, Weijia Li, Wenzhao Wu, Yi Zhao, Runmin Dong, and Le Yu. "Cross-Regional Oil Palm Tree Counting and Detection Via a Multi-Level Attention Domain Adaptation Network." ISPRS Journal of Photogrammetry and Remote Sensing 167 (September 1, 2020): 154-177. 